\title{
ANNETTE BAIER Y MICHAEL WALZER ACERCA DE LA ÉTICA NORMATIVA Y EL FILÓSOFO MORAL ${ }^{1}$
}

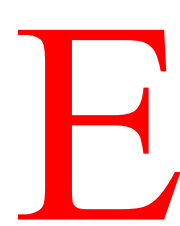

1 profesor Javier Muguerza suele repetir con cierta frecuencia que el filósofo moral no tiene por qué hacer lo que dice puesto que bastante tiene con decirlo. La afirmación provoca una doble perplejidad. La primera resulta de considerar la idea implícita de que lo propuesto o recomendado por aquel es merecedor del acatamiento de su auditorio. La segunda cuando pensamos que el hecho de su mero decir es suficiente causa de justificación para actuar inconsecuentemente.

Hoy, cuando en el ámbito de la Ética son cada vez más los que transitan del placentero mundo de la reflexión íntima en despachos académicos al inhóspito territorio de los hospitales, escuelas de negocios, asociaciones profesionales e, incluso, empresas mercantiles, se hace de nuevo necesario (una vez mas y nunca la última) indagar, por un lado, sobre el papel del filósofo moral y, por otro, sobre el carácter y objeto de la disciplina que profesa. Esto último es particularmente urgente en un momento en el que la revitalización de la Ética normativa acaecida durante los años 70 , gracias en gran medida a la obra de John Rawls y de Jürgen Habermas, parece estar en sus horas mas bajas.

Evidentemente, la cuestión es lo suficientemente compleja como para que en estas líneas pueda ser, siquiera sea mínimamente, resuelta.

\footnotetext{
${ }^{1}$ Este trabajo está dedicado al doctor Elías Díaz, el más joven de los profesores de Filosofía del Derecho, Moral y Política de la Facultad de Derecho de la Universidad Autónoma de Madrid. Su talante, honestidad y magisterio son un ejemplo y estímulo intelectual constante. Su amistad un privilegio.

La idea de presentar esta colaboración así como el tema surgió en la Universidad de Syracuse donde transcurrió para mí el curso académico 1993-1994. Quiero agradecer a los profesores Fred M. Frohock y Michael Stocker sus enseñanzas, sugerencias y comentarios a los ensayos que para sus cursos presenté y que son la base de este que ahora me ocupa y asimismo a los profesores Liborio Hierro, José Luis Colomer, Cristina Sánchez y Luis Rodríguez Abascal por sus valiosas aportaciones a esta versión final.
} 
Mi propósito es pues de alcance limitado; plantearé críticamente, tan sólo, los argumentos centrales del debate basándome en dos de los autores que, a mi entender, con mayor pregnancia se han ocupado últimamente del asunto: Annete Baier y Michael Walzer².

En la primera parte del trabajo me voy a ocupar de las posibles dificultades e inconsistencias del proyecto de ética normativa que con mayor frecuencia figura en el punto de mira tanto de dichos autores como de los que se han dado en llamar comunitaristas (entre ellos el propio Walzer). Me estoy refiriendo al constructivismo ético tal y como es entendido por John Rawls y Carlos Santiago Nino entre otros. Comprobaremos, por un lado, que las críticas de Baier y Walzer se dirigen no tanto contra ese particular modelo sino, en general, contra todo intento de teorizar sobre la justicia y, por otro, que un análisis cuidadoso del mismo junto con las reformulaciones que sus propios postuladores han esbozado en los últimos años lleva a considerar que se ha aminorado, si no anulado, la distancia con sus críticos.

Dicha polémica se encuentra indisolublemente ligada a la discusión acerca del papel del filósofo moral. Como indicaba al principio se trata de una cuestión siempre presente, implícita o explícitamente, en la historia del pensamiento (baste recordar en este sentido la archiconocida recomendación de Marx en la XI Tesis sobre Feurbach). Lo que se pone ahora en tela de juicio es ese carácter pseudo pastoral que muchos éticos contemporáneos se arrogan; bien porque es inconsistente con su atestiguada falta de compromiso personal (segunda de las paradojas iniciales) y porque la teoría moral, entendida como guiadora de la acción, es innecesaria ${ }^{3}$ o, en el mejor de los casos, irremisiblemente necesitada del auxilio de otras ciencias sociales, bien porque una vez desmontada la posibilidad de su universabilidad, al filósofo moral sólo le cabe ser «intérprete local» ${ }^{4}$. La segunda parte del escrito se centrará en el análisis de estas cuestiones.

I

Siguiendo el esquema propuesto por A. J. Ayer, son tres los posibles

${ }^{2}$ Annete Baier, «Doing without moral theory?» en Postures of the Mind. Essays on Mind and Morals. University of Minnesota Press, 1985, págs. 228-245. Michael Walzer, Spheres of Justice, Basic Books, Nueva York 1983, «Philosophy and Democracy», Political Theory, Vol. 9, n. ${ }^{\circ}$ 3, Agosto 1981, The Company of Critics. Social Criticism and Political Commitment in the Twentieth Century, Basic Books, Nueva York, 1988, Interpretation and Social Criticism, Harvard UniversitY Press, 1987.

${ }^{3}$ Baier, «Doma without Moral Theory?», págs. 232-233.

${ }^{4}$ Walzer, Spheres of Justice, pág. XIV, «Philosophy and Democracy», pág. 9. The Company of Critics..., pág. 231. Interpretation and Social Criticism, pág. 21. 
objetos de la filosofía moral ${ }^{5}$ : el estudio de la lógica del lenguaje moral ${ }^{6}$, el análisis de las teorías de lo justo o lo bueno, es decir, de las teorías justificadoras de la acción desde una perspectiva ideal o crítica, y la investigación empírica del funcionamiento de la moral positiva. El constructivismo ético vendría a situarse en la segunda de estas categorías, aunque surge a partir del «tomarse en serio», también, como más adelante veremos, la tercera de ellas; lo que no parece ser en ningún caso es una teoría metaética en el sentido de Ayer y de otros representantes de esa tradición analítica ${ }^{7}$.

Aunque con diferencias y distintos argumentos, lo que subyace en autores como G. E. M. Anscombe, Alasdair MacIntyre y la propia Annete Baier ${ }^{8}$, entre otros, es el rechazo a la teoría ética que tiene como principal objeto de análisis los principios y normas guiadoras de la acción y su justificación. Para Anscombe, tal concepción «legalista» es el resultado de la hegemonía de la versión cristianizada

${ }^{5}$ Language, Truth and Logic, Víctor González Ltd., 1936, pág. 103 (hay traducción castellana de M. Suárez, Lenguaje, verdad y lógica, Planeta Agostini, Barcelona, 1986). Ayer propone una cuarta categoría -juicios éticos reales (actual ethical judgements)- cuya configuración con respecto a las demás no resulta sencilla según sus propias palabras. En todo caso no constituyen objeto de estudio de la filosofía moral.

${ }^{6}$ El propio Ayer considera, «... que sólo la primera de nuestras categorías a saber aquella que comprende las proposiciones relativas a las definiciones de términos éticos, puede decirse que constituye filosofía ética.» op. cit., pág. 104. Asimismo. R. M. Haré, The Language of Morals, Oxford University Press, 1952, p. v. (hay traducción castellana de G. R. Carrió y E. Rabossi, El lenguaje de la moral, Universidad Autónoma de México, 1975). Refiriéndose específicamente a la teoría de la justicia de Rawls, Haré entiende, en un trabajo posterior, que precisamente el descuido y mala comprensión de aquel sobre las cuestiones de metodología filosófica, análisis ético (entendiendo por tal el estudio del significado o naturaleza de los términos morales y sus propiedades lógicas) y metodología moral hace que su teoría normativa carezca del equipamiento necesario para que sea defendible. «Rawls' «Theory of Justice» en Reading Rawls. Critical Studies on Rawls «A Theory of Justice», Norman Daniels ed., Stanford University Press, 1989. pág. 81.

${ }^{7}$ Manuel Jiménez Redondo, Constructivismo, Rawls, Nozick, Universidad de Valencia, 1983, págs. 65-66. Sí creo que existirían consideraciones metaéticas en la obra de Rawls en lo que respecta a la naturaleza de la teoría normativa y la posible continuidad o discontinuidad en relación al pensamiento científico (sobre todo en A Theor y of Justice, Harvard University Press, Cambridge 1971, págs. 46-53 -hay traducción en castellano a cargo de $\mathrm{M}^{\mathrm{a}}$. D. González. Teoría de la justicia, Fondo de Cultura Económica, México, 1979- y en «Kantian Constructivism in Moral Theory». The Journal of Philosophy, Vol. 78, n. ${ }^{\circ}$ 9, septiembre 1980, pág. 554). En contra de esta idea. Stephen Darwall, Allan Gibbard y Peter Railton, «Towards Fin de Siecle Ethics», The Philosophical Review, Vol. 101, n. ${ }^{\circ}$ 1, january 1992, pág. 140.

${ }^{8}$ G. E. M. Anscombe, «Modern Moral Philosophy», en Ethics, Religion and Politics, Collected Philosophical Papers, Vol. 3. Basil Blackwell, 1981. Alasdair MacIntyre, Tras la Virtud, Ed. Crítica, 1987. Annete Baier con acentos más humeanos, «Doing witout Moral Theory?». 
de la ética aristotélica ${ }^{9}$. Con la pérdida de esa matriz (de la posibilidad de última apelación a la autoridad divina debida al proceso de secularización en Occidente) resultan vanos los intentos racionalistas de fundamentación de la moral, particularmente el del contractualismo ${ }^{10}$. En parecidos términos, según MacIntyre el discurso moral que heredamos es fragmentado e incomprensible por la pérdida del concepto de virtud que viene a funcionar como puente entre «el hombre tal-cual-es y el hombre como-podría-ser-si-realizara-su-telos ${ }^{11}$.

Annete Baier, por su parte, apunta aún más alto: todo intento de teorizar sobre la justicia (el neocontractualismo de corte kantiano paradigmáticamente) es inútil. Baier entiende por teoría normativa un sistema de principios morales, en el cual los menos generales se derivan de los más abstractos que nos indican como debemos actuar. Según dicha autora, teorías genuinas y útiles son las científicas; en la esfera del saber práctico (como por ejemplo la cocina o la ingeniería) no tiene sentido hablar de ellas ${ }^{12}$.

Me interesa constatar en este momento, antes de entrar en las críticas y deficiencias señaladas al proyecto constructivista, que esa frecuente apelación a tiempos en que la filosofía moral era genuina es sólo aparentemente neutral. Apenas se esconde, por parte de los mencionados autores, el intento de recuperar el aristotelismo o, en el caso de Baier, una teoría ética de raíz humeana. Se trata en definitiva de modelos distintos de entender el fenómeno moral y su estudio a los que cabría también extender legítimamente, creo, la acusación de querencia guiadora y «teorizante».

Como antes indicaba, el constructivismo ético toma como punto de partida, en palabras de Nino, la inescindible relación entre moralidad crítica y moralidad positiva. Si, en definitiva, toda actitud moral, como asumirían algunos de los llamados comunitaristas, no es sino el reflejo de las prácticas sociales vigentes, resulta imposible

${ }^{9}$ Op. cit., pág. 30 .

${ }^{10} \mathrm{Ibid}$, pág. 38.

${ }^{11}$ Aunque expresando diferencias, él mismo reconoce su deuda con las tesis de Anscombe. Tras la virtud, págs. $78,79,83,85$.

${ }^{12}$ Op. cit., págs. 232-233. Hay teorías sobre la nutrición y recetas de cocina así como matemáticas, física y química para poder construir, por ejemplo, puentes. Sería una extraña empresa, arguye Baier, tratar de encontrar en las recetas o en la construcción de puentes los principios aplicados o unificar las reglas de la cocina o de la ingeniería en un gran sistema para así poder derivar nuevas recetas, menús o puentes. Richard B. Brandt define, igualmente, la ética normativa, «... como estudio filosófico, una investigación dirigida a establecer y defender como válido o verdadero un conjunto completo y simplificado de principios éticos generales y también algunos principios menos generales que son importantes para lo que podríamos denominar -proporcionar el fundamento ético» de las instituciones humanas más importantes». Teoría Ética, Alianza Editorial, Madrid, 1982, págs. 22-23. 
saber qué queremos decir cuando hablamos de progreso, dilema o arrepentimiento morales $\mathrm{y}$, sobre todo, entender la distinción entre dichas actitudes de otras que todos convenimos en identificar como religiosas, de trato social, etc... Como apunta Carlos Santiago Nino, «La moral social o positiva es el producto de la formulación y aceptación de juicios con los que se pretende dar cuenta de principios de una moral ideal. Sin la aspiración de actuar y juzgar de acuerdo con una moral ideal no habría moral positiva» (el énfasis es del autor) ${ }^{13}$. Es decir, la moral social actúa como plataforma o referente para los juicios críticos y, a su vez, aquella acaba siendo conformada por éstos. Además, es tomando como base el discurso moral vigente como podemos identificar ciertos rasgos estructurales del mismo como distintivos frente a otras prácticas sociales.

Esta es la idea que subyace a los «experimentos mentales» como el de la posición original de Rawls. Los principios de justicia son el resultado del diseño de un procedimiento discursivo que incorpora aquellos rasgos que antes mencionaba ${ }^{14}$. No son la manifestación de «verdad moral» alguna, como pretendería el intuicionismo racional del que a toda costa quiere distanciarse Rawls, y de ahí que estén sometidos a un proceso de ajuste continuo (back and forth) con nuestras intuiciones morales hasta lograr la situación de coherencia que Rawls denomina «equilibrio reflexivo». Ante la eventualidad de una intuición moral que no casase con el resultado del procedimiento, el modelo constructivista exigiría el abandono de aquélla. No cabría, como sucedería si adoptamos la visión intuicionista, convivir con la incongruencia con la esperanza de refinar la teoría ${ }^{15}$.

Otra característica que conviene resaltar, es que los principios tienen como objeto de aplicación la que Rawls denomina «estructura básica» de la sociedad entendida como, «... la forma en la cual las instituciones sociales más importantes se acoplan en un gran sistema, y como ellas asignan los derechos y deberes fundamentales y conforman la división de las ventajas que surgen a través de la cooperación social. Así, la constitución política, las formas de propiedad legalmente reconocidas, y la organización de la economía y la naturaleza de la familia, pertenecen todas a la estructura básica ${ }^{16}$. Desde esta perspectiva, el constructivismo de Rawls sería inmune a la crítica

${ }^{13}$ Ética y Derechos Humanos, Ariel, Barcelona, 1989, pág. 93.

${ }^{14}$ Lo que Rawls denomina «justicia procesal pura». «Kantian Constructivism in Moral Theory», pág. 516. A Theory of Justice, pág. 85.

${ }^{15}$ A Theory of Justice, pág. 49. Asimismo, Ronald Dworkin, Taking Rights Seriously, Harvard University Press, Cambridge 1977, pág. 161 (hay traducción castellana de Marta Guastavino, Los derechos en serio, Ariel, Barcelona, 1989).

${ }^{16}$ Political Liberalism, Columbia University Press, Nueva York 1993, pág. 258. Asimismo, A Theory of Justice, pág. 7. 
formulada por Baier contra aquellas teorías normativas que pretenden indicarnos lo que debemos hacer. El propósito de Rawls es más modesto (o quizá mucho más ambicioso), pues no pretende guiarnos ni dar soluciones para los conflictos morales concretos que surgen en nuestra vida cotidiana ${ }^{17}$.

Pero es precisamente por cómo entiende el autor de A Theory of Justice otra de las limitaciones de alcance de su teoría desde donde empiezan a surgir los problemas. Rawls, posiblemente frente a Nino y Dworkin, insiste en que su propuesta teórica de justificación de los principios de justicia es aplicable, dicho simplificadamente, a sociedades democráticas modernas; los principios de justicia son: «... los principios más razonables para nosotros, dada nuestra concepción de las personas como libres e iguales, y miembros plenamente cooperantes de una sociedad democrática ${ }^{18}$. Si esto es así, resulta difícil entender, como apunta Dworkin ${ }^{19}$, la necesidad del complejo y abstracto experimento mental diseñado por Rawls para justificar principios que ya de hecho se encuentran incorporados en nuestro sentido de la justicia y nuestras convicciones como ciudadanos de regímenes democráticos ${ }^{20}$.

No parece, sin embargo, admisible esta aproximación en palabras del propio Rawls, puesto que la concepción pública de la justicia y el entendimiento de la libertad e igualdad no son pacíficos. Sigue siendo preciso incluso para nosotros (destinatarios, al parecer, de su concepción de la justicia) lograr una base para la justificación

${ }^{17}$ El alcance limitado de su propuesta es contrastado por el propio Rawls frente a otras doctrinas que sí tendrían carácter comprensivo (particularmente el utilitarismo). Political Liberalisin, págs. 260-261. Que la extensión de los principios más allá de la estructura básica no es posible ni deseable es destacado por Thomas E. Hill, Jr., «Kantian Constructivism in Ethics», Ethics, n. ${ }^{\circ}$. 99, july 1989, pág. 753.

18 «Kantian Constructivism...», págs. 518, 554. Political Liberalism, pág. 28.

${ }^{19}$ Taking Rights Seriously, pág. 156.

${ }^{20}$ Esta inconsistencia es también apuntada por Manuel Jiménez Redondo, op. cit., págs. 95-96. La posición de Rawls en este punto (la naturaleza de la teoría de la justicia) no resulta fácil de entender. Los principios derivan de una teoría de la justicia, entendida como teoría de los sentimientos morales, y nos ayudan a entender nuestro sentido de la justicia, A Theory of Justice, págs. 46, 51. Uno de los problemas de esta equiparación es que, como ha apuntado Gilbert Harman, las teorías éticas, frente a las científicas, no nos sirven para entender por qué observamos como bueno o malo, correcto o incorrecto el hecho moral que observamos. Por ejemplo, la mecánica newtoniana, como teoría de las ciencias físicas, explica por qué observamos la caída de los cuerpos, siempre que admitamos que el hecho de que el cuerpo cae es verificable. El imperativo categórico kantiano nos indica que todo ser humano es un fin en sí mismo y que no debe ser usado como medio de nada. Dicho principio no nos ayuda a explicar por qué observamos como algo execrable la tortura de un niño. The Nature of Morality. An Introduction to Ethics, Oxford University Press, Nueva York, 1977, pág. 7. 
pública $^{21}$ ¿Por qué no extender entonces lo que resulta finalmente ser su propuesta normativa a sociedades no democráticas modernas, donde tampoco existe ese consenso? Una respuesta posible vendría de considerar que dicha extensión es inviable porque también los rasgos fundamentales que sirven de apoyo para el diseño de la posición originaria no lo son de todo discurso moral, sino particulares del nuestro. No es así, según el propio Rawls, porque «... las condiciones incorporadas en la descripción de la posición original son las que de hecho aceptamos. Si por contra no lo hacemos, entonces podamos quizá ser persuadidos para hacerlo a través de la reflexión filosófica $)^{22}$. ¿Cómo,? Parecería que, por la inescindible relación entre moralidad positiva y crítica que sirve de punto de partida del modelo antes señalado, los elementos estructurales (que podríamos denominar «materiales de construcción») resultan de considerar el discurso moral vigente. Nos veríamos entonces obligados, siguiendo la propia lógica interna, a contrastarlos con criterios ideales, y avocados, por tanto, a un proceso infinito que recordaría en gran medida a la open-ended question de Moore o al conocido como «trilema de Münchhausen», ilustrativo de la imposibilidad de una última fundamentación en la teoría moral ${ }^{23}$. El tercer cuerno de dicho trilema (el primero ya lo acabo de mencionar y es el de la regresión ad infinitum) es el de la ruptura arbitraria del proceso de inferencias deductivas; así lo ha señalado Thomas Nagel: «Cualquier situación de elección hipotética que requiera acuerdo entre las partes tendrá que imponer fuertes restricciones en las bases de la elección, y estas restricciones pueden justificarse sólo en términos de una concepción de lo bueno. Es uno de esos casos en que no cabe neutralidad, porque la neutralidad necesita tanta justificación como cualquier otra posición $»^{24}$. El intento de evitar cualquiera de las alternativas del trilema por parte de Rawls es desalentadoramente similar a la solución adoptada por el propio baron de Münchhausen para salir del fango (tirar de sus propios cabellos hacia arriba): «... sólo los principios sustantivos que especifican el contenido de lo políticamente correcto y la justicia son construidos. El procedimiento en sí es simplemente puesto (laid out) usando como puntos de partida las concepciones básicas de la sociedad y la persona, los principios de la razón práctica y el papel público de una concepción política de la justicia» ${ }^{25}$. Lo que presumiblemente debería ser el resultado final del procedimiento

${ }^{21}$ «Kantian Constructivism in Moral Theory», pág. 569.

${ }^{22}$ A Theory of Justice, pág. 21.

${ }^{23}$ El propio Nino apunta este problema. Ética y Derechos Humanos, pág. 106.

${ }^{24}$ «Rawls on Justice» en Reading Rawls. Critical Studies on Rawls «A Theory of Justice», pág. 9.

${ }^{25}$ Political Liberalism, pág. 104. 
es tomado, al mismo tiempo, como punto de partida con lo cual se incurre en la segunda de las odiosas alternativas del trilema: la incursión en un razonamiento circular.

Esta misma insistencia mía por tratar de bosquejar donde se apoya finalmente el modelo heurístico del constructivismo es lo que sirve a Apel y Habermas para establecer, de forma retorsiva, el fundamento de la práctica discursiva y del presupuesto de universalidad como exigencia pragmático-trascendental o universal (en el caso de Habermas $)^{26}$; pragmática puesto que de lo que se trataría es de hacer ver al oponente-escéptico que su pregunta acerca del fundamento de la discusión en el marco de esta misma es autocontradictoria, y trascendental ya que lo que se pretende establecer son las condiciones de posibilidad de dicha práctica. Obtendríamos de esta forma ese «principio puente» de la universalidad que establece que, «... únicamente pueden aspirar a la validez aquellas normas que consiguen (o puedan conseguir) la aprobación de todos los participantes de un discurso práctico» ${ }^{27}$. La corrección moral estaría pués dada por el consenso. Este es el corolario de lo que Nino denomina constructivismo ontológico frente al cual opone un constructivismo de carácter epistemológico, «... que consiste en sostener que si bien la validez de los juicios morales no está dada por el resultado del discurso real sino por sus presupuestos, ese resultado es una forma confiable de conocer los principios válidos $)^{28}$ (el énfasis es del autor). Es por ello, sin duda, por lo que Nino pasa ahora a indicar que, siguiendo la tipología rawlsiana sobre la justicia procedimental, el discurso moral es un caso de justicia procesal instrumental, es decir, habría un criterio independiente de validez (de ahí que no sea pura) el cual es más fiablemente cognoscible a través del resultado del procedimiento $^{29}$. La verdad es que no resulta fácil discernir esta tesis de Nino. A mi entender no parece muy congruente afirmar que un resultado inválido puede ayudar a conocer principios válidos. En una situación ideal como la de la posición original de Rawls o la comunidad ideal de diálogo habermasiana, se supone que los resultados logrados -los principios- son válidos (si no fuera así estaríamos de nuevo avocados,

\footnotetext{
${ }^{26}$ Conciencia moral y acción comunicativa, Península, Barcelona, 1985, págs. 109-110.

${ }^{27}$ Op. cit., pág. 117.

${ }^{28}$ El constructivismo ético, Centro de Estudios Constitucionales, Madrid, 1989, pág. 103.

${ }^{29}$ Para una excelente explicación de la evolución de Nino en lo referente al valor de la democracia como sucedáneo del discurso moral y su encaje en las tipologías de la justicia procesal, ver el artículo de Angeles Ródenas. «Sobre la justificación de la democracia en la obra de Carlos S. Nino», Doxa, 10, 1991, págs. 279-293.
} 
como antes se expuso, a una regresión al infinito). Cuestión distinta es la comprobación de la corrección de las soluciones alcanzadas en la práctica discursiva real o de nuestras intuiciones morales que se hará, como bien dice Nino, constatando si se han respetado las restricciones formales de imparcialidad, publicidad, etc..., pero eso no significa que el constructivismo sea meramente epistemológico. Los principios de justicia de Rawls son propuestas normativas para su posterior aplicación una vez levantado el velo de la ignorancia y así mismo ocurre con las condiciones del diálogo moral de Habermas. Considero que, en ambos casos, la teoría ética constructivista puede proporcionar principios morales (no meramente formales puesto que de ellos pueden seguirse coherentemente las apuestas por la dignidad de la persona, su autonomía e igual consideración) siempre que logre concluir plausiblemente que los elementos estructurales que toma como prius de la situación hipotética son derivados lógicamente a través de la pragmática y empíricamente con el auxilio del resto de las ciencias sociales.

Es en este aspecto donde las tesis de Baier y Anscombe adquieren plausibilidad y convergen, en cierto sentido, con Nino cuando este propone que alcancemos un «test independiente» que corrobore la forma en que idealizamos el discurso moral positivo ${ }^{30}$. Ambas nos compelen a que echemos mano de la sociología y la psicología para conocer con mayor solvencia teórica el desarrollo de nuestra competencia y sentimientos morales, si es que queremos desarrollar una teoría ética con cierto fundamento: «En la filosofía actual se requiere una explicación acerca de cómo un hombre injusto es un mal hombre, o una acción injusta una mala acción; a la ética le corresponde dar esa explicación; pero no puede siquiera empezar a darse hasta que no estemos equipados con una filosofía de la psicología plausible ${ }^{31}$. Baier por su parte apela, además, a la historia: «Salvo que conozcamos el destino de las comunidades que tratan de implantar y vivir bajo los principios morales que consideramos, ¿cómo podemos tener una opinión empíricamente contrastada acerca de su plausibilidad? El destino de las comunidades que trataron de vivir bajo aquellos principios, su éxito o fracaso al transmitirlos a las siguientes generaciones, no es decisivo, por supuesto, para que aquellos principios sean válidos en este momento para nosotros, pero parece ser un dato relevante para el filósofo moral. Nuestras reflexiones morales serán mera especulación a no ser que estén históricamente informadas» ${ }^{32}$. Que la «sociobiología», las tesis de Kohlberg, acerca del

${ }^{30}$ Ética y Derechos Humanos, págs. 106-107.

${ }^{31}$ G. E. M. Anscombe, Modern Moral Philosophy, pág. 29.

32 «Doing without Moral Theory?», pág. 242. 
desarrollo moral o la ciencia histórica puedan dar respuestas firmes para determinar cuáles son esos rasgos ineludibles de la moralidad es algo que está todavía por ser demostrado y que excede lo que yo aquí me propongo (baste en este punto mencionar las muy contundentes críticas dirigidas por parte de algunas teóricas feministas como Carol Gilligan contra los estudios de Kohlberg ${ }^{33}$ ). Lo que en todo caso sí parece innegable es que el análisis de esa realidad discursiva precisa del complemento de otros conocimientos que no son exclusivamente los propios de la filosofía moral y así evitar esa situación de autismo metodológico que con tanta frecuencia ha denunciado Elías Díaz: «... una teoría de la justicia, donde la razón tiene una función central, no puede ser nunca, y mucho menos hoy, un discurso abstracto, ahistórico y en (aparente) incomunicación con la realidad social, económica, política o cultural ${ }^{34} \gg$.

II

Hemos visto en la primera parte las dificultades asociadas a una teoría ética que no tenga en cuenta las particularidades del discurso moral positivo, y que aún tomándolas en consideración, no asuma que para ello ha de acudir al auxilio de otras disciplinas de las ciencias sociales para romper el círculo vicioso que genera la construcción de modelos de elección hipotética como la posición original de Rawls.

El filósofo moral puede ser, de acuerdo con la tipología establecida por Michael Walzer, descubridor, inventor o intérprete ${ }^{35}$. La primera de las posibilidades ilustra la actitud del otrora profeta portador de la buena nueva revelada. Correponde, pues, como indicaba anteriormente, a la versión secularizada de la moral de leyes y máximas que encuentran ahora en la Razón su último tribunal de apelaciones. El inventor, por contra, es el legislador moral que, imitando a Dios, se propone avanzar los principios adecuados para lograr la mayor felicidad para el mayor número, la justicia entendida como equidad, etc... y al mismo tiempo proveer un baremo correctivo universal para las distintas moralidades vigentes. Este proyecto de elaboración de un «esperanto moral» es severamente criticado por Walzer quien, de nuevo, se pregunta por su necesidad: «¿Por qué los nuevos principios

\footnotetext{
${ }^{33}$ Carol Gilligan, From a Diferent Voice, Harvard University Press, Cambridge, 1982.

${ }^{34}$ Ética contra política. Los intelectuales y el poder, Centro de Estudios Constitucionales, Madrid, 1990, pág. 23.

${ }^{35}$ Interpretation and Social Criticism, pág. 3. Asimismo, en Spheres of Justice, pág. XIV.
} 
inventados deben gobernar las vidas de las personas que ya comparten una cultura moral y hablan un lenguaje natural?» ${ }^{36}$. Ninguno de los dos caminos de la filosofía moral -el descubrimiento o la invención- dan buena cuenta de como se experimenta cotidianamente la moralidad. Son además espejismos intelectuales o, incluso, conceptos autocontradictorios, puesto que, continúa Walzer, los productos de la invención o descubrimiento acaban siendo irremediablemente similares a la moral que efectivamente es. El hecho del desacuerdo moral, dato definitivo que encumbra a los que optan por alguna de las dos alternativas rechazadas por el autor que comentamos, sirve precisamente a este para apostar por la interpretación: «La experiencia de la discusión moral es mejor entendida en el modo interpretativo. Lo que hacemos cuando discutimos es dar cuenta de la moralidad realmente existente ${ }^{37}$. Ello obliga a que el filósofo moral vuelva la mirada hacia los concretos mores, a que reconozca «el componente no intelectual de la moralidad vulgar $u$ ordinaria ${ }^{38}$. Se convierte así en un interlocutor más, en uno de los muchos intérpretes. El propio Habermas en una visión menos drástica llega también a afirmar: «Todos los contenidos, incluso aunque afecten a normas de acción fundamentales, han de hacerse dependientes de discursos reales... El teórico moral puede participar en ellos como afectado y, en su caso, como experto, pero no puede dirigir por su cuenta tales discursos. Una teoría que se extiende a ámbitos de contenido, como la teoría de la justicia de Rawls, debe entenderse como una aportación al discurso que se da entre sus ciudadanos» ${ }^{39}$ (el énfasis es del autor).

El propio Walzer es consciente de las muy fundadas sospechas de holismo ético y metodológico que rezuma su propuesta. En concreto, parece muy díficil seguir hablando, con el cuadro que hemos pintado, de conceptos tales como progreso moral y crítica social. En realidad las cosas no resultan tan dramáticas. Volvemos a estar de nuevo, a poco que inspeccionemos con detenimiento el esquema walzeriano, con la sempiterna tensión moralidad positiva-moralidad crítica. La vía del descubrimiento no resulta tan denostada y muchos de los

\footnotetext{
${ }^{36}$ Interpretation and Social Criticism, pág. 14.

${ }^{37}$ Ibid. pág. 21.

${ }^{38}$ Annette Baier, «Extending the Limits of Moral Theory», The Journal of Philosophy, Vol. 83, n. ${ }^{\circ}$ 10, octubre 1986, pág. 542.

${ }^{39} \mathrm{Op}$. cit., pág. 118. La versión más drástica correspondería a los pasajes de Baier en los que, para rechazar la visión de la moralidad que avanza una ética normativa de corte constructivista, formula un original «imperativo categórico», síntesis de Hume y Kant que rezaría: acepta aquella teoría moral que implica el tipo de enseñanza que una madre estaría dispuesta a transmitir a sus hijos. «Extending the Limits of Moral Theory», pág. 541.
} 
presupuestos y corolarios de su máximo representante (el último Rawls) podrían, sin ser excesivamente forzados, pasar a engrosar el postulado de la interpretación, que no es en ningún caso una mera descripción de la moralidad realmente existente ${ }^{40}$. Walzer admite, por ejemplo, que el crítico social ha de distanciarse (el problema es determinar cuánta distancia de separación es necesaria) y que no toda interpretación es admisible (cuál sea el criterio de admisibilidad es algo que el propio autor reconoce no saber $)^{41}$.

A poco que nos descuidemos, sin embargo, y del descubrimiento «no autoritario» o interpretación que no excluye la crítica pasemos a afirmar que los criterios de justicia son puramente locales, esto es, que las acciones e instituciones se justifican porque son las que son o las que siempre han sido, las contradicciones son insuperables. El mismo Michael Walzer, ejemplifica este deslizamiento de consecuencias devastadoras cuando defiende el régimen de igualdad compleja frente a la igualdad simple como forma más «justa» de distribuir los recursos ${ }^{42}$ : si en una sociedad determinada (por ejemplo en la India) el entendimiento compartido de la justicia es el contrario (la igualdad simple que postula la dominación) esta «... vendrá en auxilio de la desigualdad» ${ }^{43}$. Sólo desde dentro a través de la interpretación o externamente si conectamos nuestra crítica con sus propios mores, cabría modificar esa situación. Ese respeto por las concepciones particulares de lo justo exige, por tanto, un principio universal de no interferencia. De otra manera, se produciría la siguiente paradoja: (1) La concepción de la justicia distributiva es particular; (2) En la sociedad X, la concepción compartida es que los principios de la justicia distributiva son universales y coercibles. Dicho entendimiento sería justo por (1) aunque niega $(1)^{44}$. El propio Walzer no rechaza la posibilidad de un código de moralidad mínima universal y la propia lógica interna de su planteamiento así lo exige. Asume, asimismo, que la práctica de la crítica social es moralmente valiosa ${ }^{45}$.

Las diferencias con los éticos constructivistas son, por tanto, una cuestión de mayor o menor insistencia en la importancia de la eticidad

\footnotetext{
29.

${ }^{40}$ Supone también glosa, construcción, elucidación, etc... Interpretation and Social Criticism, pág.

${ }^{41}$ Ibid, págs. 36, 49.

${ }^{42}$ La igualdad de acuerdo a Walzer, obliga a proscribir la dominación entendida como la primacía de un único criterio relevante para la distribución de todos los bienes, sin prestar atención al significado intrínseco de los mismos. De ahí que se proponga la igualdad compleja. Spheres of Justice, págs. 10, 11, 17 y 19.

${ }^{43}$ Ibid, pág. 313.

${ }^{44}$ Un argumento parecido se puede encontrar en Stephen Mulhall and Adam Swift, Liberals and Communitarians, Blackwell Publishers, Oxford 1992, pág. 145.

${ }^{45}$ Interpretation and Social Criticism, pág. 62.
} 
o de mayor o menor pasión por la justificación, de considerar qué discurso y recurso le resulta finalmente más eficaz al crítico en función de su auditorio y, sobre todo, de actitud intelectual. Pero todo ello implica un presupuesto ineludible, cual es el que todos podamos efectivamente seguir discutiendo, matizando y criticando. Una democratización de dicha empresa, su dejar de ser asunto exclusivo de los profesionales de la filosofía moral, me parece a mí una de las aportaciones atendibles tanto de Baier como de Walzer, pues no hace sino reforzar la idea de la igualdad de trato y consideración de todos. Por contra, la insistencia en la inutilidad o implausibilidad de la ética normativa constructivista, con las matizaciones que he tratado de perfilar a lo largo de estas páginas, resulta ser en mi opinión una idea autocontradictoria puesto que negaría en último término la posibilidad de que la discusión moral (en la que Baier y Walzer sin duda participan) prosiga. Como asevera Carlos Santiago Nino refiriéndose a la filosofía moral, «... en la medida en que ella se proponga esclarecer las reglas constitutivas de una institución que satisface ciertas funciones sociales sumamente valiosas, se fortalecerá la operatividad y eficacia de esa institución, puesto que los que participan en ella (todos nosotros cuando discurrimos acerca de la justificación de una acción o institución) tendrán una visión más perspicua del "juego" que practican y lo harán mejor». ${ }^{46}$

${ }^{46}$ El constructivismo ético, pág. 71. 
$\triangle$ 